\title{
PENGEMBANGAN SISTEM INFORMASI RESERVASI DAN CUSTOMER RELATION MANAGEMENT PADA RESTORAN 3 WISE MONKEYS
}

\author{
Laurentia Anggun P. ${ }^{1}$, Kristina G. Simanjuntak ${ }^{2}$, Kusno Prasetya ${ }^{3}$, Andree E. Widjaja ${ }^{4}$ \\ Mahasiswi Universitas Pelita Harapan ${ }^{1}$, Dosen Universitas Pelita Harapan ${ }^{2,3,4}$ \\ Jl. M.H. Thamrin Boulevard 1100, Lippo Karawaci, Tangerang, Banten 15811 \\ Sur-el : laurentiaanggunp@gmail.com ${ }^{1}$, kristinagloria.simanjuntak@gmail.com², \\ kusno.prasetya@uph.edu ${ }^{3}$, andree.widjaja@uph.edu ${ }^{3}$
}

\begin{abstract}
The current competitions between businesses is getting more intense, one of those competitions is in restaurant business. 3 Wise Monkeys is a restaurant that is trying to improve its customer service. One of the main problems is the unavailability of tables when they come to the restaurant, whcih can affects customer's judgement. This research aims to help the customer and restaurant owner by designing an online reservation system to book the table and food. The benefit of the system for the customer is that they can choose their table and the menu even before they arrive to the restaurant. Furthermore, there is doorprize feature for the customers who make online reservatoin, making them want to come back in the future and use the online system. The benefit for the restaurant owner is the system can produce informations regarding the number of members, what is the favorite menus, and what time is the busiest hour for the restaurant.
\end{abstract}

Keywords: Information systems, Online reservation, Restaurant, Online systems, CRM

\begin{abstract}
Abstrak : Banyaknya bidang usaha saat ini membuat persaingan antar usaha semakin ketat, salah satunya persaingan antar restoran. 3 Wise Monkeys merupakan restoran yang ingin meningkatkan kualitas pelayanannya. Tidak tersedianya meja menjadi masalah utama bagi restoran karena hal tersebut dapat mempengaruhi penilaian pelanggan. Tujuan dari penelitian ini adalah untuk membantu pelanggan dan pemilik restoran dengan merancang sistem reservasi online untuk memesan meja dan makanan secara online. Hasil dari penelitian ini adalah Sistem Informasi Reservasi Online dan Customer Relation Management Restoran 3 Wise Monkeys. Dengan adanya sistem tersebut, pelanggan merasa terbantu karena dapat melakukan pemilihan tempat duduk dan menu makanan sebelum pelanggan tiba di lokasi restoran. Pelanggan juga tertarik untuk kembali lagi dengan adanya program berhadiah bagi pelanggan yang sudah melakukan reservasi secara online. Keuntungan bagi pemilik restoran adalah dapat mengetahui berapa banyak pelanggan yang sudah menjadi anggota, menu apa saja yang sering dipesan oleh pelanggan, dan jam sibuk restoran.
\end{abstract}

Kata kunci: Sistem Informasi, Reservasi, Restoran, Online, CRM

\section{PENDAHULUAN}

Teknologi masa kini sudah menjadi kebutuhan primer bagi kebanyakan orang, bahkan sudah tidak dapat ditinggalkan. Berbagai macam kalangan, profesi, dan usia sudah membutuhkan manfaat dari teknologi. Banyak bidang usaha yang besar, menengah, dan kecil sudah bergantung dengan teknologi dalam menjalankan aktivitas bisnisnya. Salah satu contoh bidang usaha yang membutuhkan peran teknologi yaitu restoran. Restoran saat ini sudah menggunakan teknologi untuk menunjang kelancaran bisnisnya [1]. Restoran membutuhkan sistem Point of Sales (POS) yang berfungsi untuk menghitung penjualan [2] dan media sosial sebagai sarana promosi [3]. Selain itu ada juga sistem reservasi online untuk restoran guna meningkatkan kepuasan 
pelanggan. Berdasarkan survey dari 696 restoran setidaknya satu banding tiga dari pelanggannya memilih untuk melakukan reservasi online. Bagi para partisipan, reservasi online dirasa lebih efektif dibandingkan dengan reservasi melalui telepon. OpenTable merupakan salah satu aplikasi reservasi online yang peminatnya meningkat dalam kurun waktu tujuh tahun. Sistem reservasi online ini tidak hanya menguntungkan bagi pelanggan saja tetapi restoran. Beberapa keuntungannya adalah mengurangi biaya operasional, meningkatkan pendapatan restoran, dan meningkatkan kualitas pelayanan [4].

Setiap pemilik restoran memiliki strategi tersendiri untuk meningkatkan kualitas dan pelayanan kepada para pelanggannya. 3 Wise Monkeys merupakan salah satu restoran Jepang yang terletak di Jakarta Selatan ini selalu meningkatkan kualitas makanan maupun pelayanan untuk meningkatkan kepuasan bagi para pelanggannya. Peningkatan kualitas ini berguna untuk memuaskan para pelanggannya apabila dapat terlayani dengan baik [5]. 3 Wise Monkeys juga sudah memanfaatkan teknologi sebagai sarana promosi salah satunya dengan menggunakan instagram. Banyaknya pengguna media sosial menyebabkan 3 Wise Monkeys dikenal oleh banyak orang, sehingga restoran ini selalu dipenuhi oleh para pelanggannya.

Salah satu contoh masalah yang dihadapi oleh 3 Wise Monkeys yaitu mengenai ketersediaan meja. Ketersediaan meja juga mempengaruhi penilaian pelayanan, pelanggan berharap saat datang dapat duduk di meja yang tersedia [5]. Banyak pelanggan yang kecewa ketika pelanggan harus menunggu tersedianya meja. Masalah lain ketika pelanggan sudah datang namun menu yang akan dipesan sudah habis terjual. Untuk mengatasi masalah tersebut, saat ini pihak restoran mencoba mensosialisasikan nomor telepon yang dapat dihubungi untuk melakukan reservasi melalui telepon. Kesalahan dalam pencatatan makanan sering terjadi karena kesalahan komunikasi antara pelanggan dan pelayan [7]; [6]. Pihak restoran saat ini belum dapat melakukan program loyalitas bagi pelanggan yang sudah sering datang ke restoran dikarenakan tidak mengetahui data pelanggan.

Adapun dalam penelitian ini, rumusan masalah yang dibahas adalah sebagai berikut:

1) Reservasi meja masih dilakukan secara manual melalui telepon sehingga memungkinkan terjadinya kesalahan pencatatan.

2) Pelanggan tidak dapat memilih meja yang diinginkan karena pelanggan tidak dapat melihat posisi meja yang terdapat di restoran 3 Wise Monkeys.

3) Restoran 3 Wise Monkeys belum dapat memberikan hadiah bagi pelanggan yang sering datang ke restoran ini, karena pihak restoran tidak menyimpan data para pelanggannya.

Tujuan penelitian ini adalah membangun sistem informasi yang dapat :

1) Membantu pelanggan dalam memesan tempat dan makanan secara online sehingga dapat dipesan sebelum tiba di lokasi.

2) Membantu pelanggan melihat meja dan makanan yang masih tersedia. 
3) Menghindari kesalahan dalam pencatatan pemesanan makanan dan tempat duduk yang sudah dipesan.

4) Dapat mengolah data pelanggan untuk memberikan program berhadiah kepada pelanggan.

\section{METODOLOGI PENELITIAN}

Dalam melakukan penelitian ini, ada dua tahap penelitian yang harus dilalui yaitu pengumpulan data dan pengembangan sistem berdasarkan data yang telah dikumpulkan. Metode yang dipakai untuk melakukan pengumpulan data adalah:

1) Studi literatur, merupakan teknik pengumpulan data dengan membaca buku atau literatur yang berhubungan dan dapat mendukung penelitian.

2) Observasi, yaitu melakukan kunjungan langsung ke restoran dengan cara melakukan reservasi melalui telepon dan memesan makanan di lokasi. Selain itu, observasi yang dilakukan dengan meninjau sistem yang saat ini digunakan oleh restoran.

3) Wawancara, yaitu metode pengumpulan data dengan melakukan tanya jawab dan konsultasi dengan pemilik restoran untuk mendapatkan informasi yang berhubungan dengan penelitian.

Selanjutnya, untuk pengembangan aplikasi, digunakan metodologi System Development Life Cycle (SDLC), metode yang digunakan adalah Rapid Application Development (RAD). Metode ini dipilih karena sistem informasi yang dikembangkan tidak menggantikan sistem lama. Metode ini juga memungkinkan pengguna untuk terlibat aktif dalam tahap desain dan testing sehingga sistem dan aplikasi yang dihasilkan dapat lebih tepat dalam memenuhi kebutuhan pengguna.

\subsection{Teori Pendukung}

Bagian ini akan menjelaskan mengenai teori pendukung yang dipakai dalam penyelesaian penelitian ini:

\subsubsection{Customer Relation Management (CRM)}

Customer Relation Management dapat didefinisikan sebagai metode untuk memahami perilaku pelanggan melalui intensitas komunikasi dengan pelanggannya [8], agar dapat memperbaiki performa sehingga dapat menarik pelanggan dan meningkatkan loyalitas. Kunci kesuksesan suatu perusahaan adalah baiknya hubungan antara pelanggan dengan perusahaan, dengan mengerti apa yang dibutuhkan oleh pelanggan. Berikut ini merupakan beberapa konsep mengenai CRM (Milovic, 2012), antara lain:

1) Meningkatkan kemampuan untuk memilih pelanggan.

2) Mengintegrasikan penawaran kepada pelanggan.

3) Meningkatkan efisiensi dan efektivitas penjualan.

4) Menyesuaikan produk atau jasa yang ditawarkan kepada pelanggan.

CRM merupakan konsep dasar dari strategi pemasaran yang digabungkan antara 
proses internal, fungsi, dan jaringan eksternal [8]. Hal-hal yang perlu diperhatikan terkait dengan CRM adalah apa yang akan dijual, siapa yang akan membeli produk tersebut, bagaimana menciptakan nilai jual lebih kepada pelanggan, dan bagaimana kita menyampaikan informasi kepada pelanggan. Beberapa jenis CRM, antara lain: Operational CRM, Analytical CRM, Sales Intelligence CRM, Campaign Management, collaborative CRM, dan Consumer Relationship CRM.

Dengan adanya dukungan teknologi masa kini, maka teknologi informasi dimanfaatkan untuk merancang ulang proses bisnis, dengan menetapkan metode yang inovatif agar dapat menghubungkan perusahaan dengan pelanggan dan internal perusahaan. Keuntungan dari CRM terlihat pada peningkatan pendapatan dan keuntungan, dan pengurangan biaya. Siklus CRM seperti Gambar 1 dapat membantu mendapatkan keuntungan dari CRM. Dalam perusahan harus memiliki visi yang jelas terlebih dahulu, dari visi tersebut maka perusahan dapat menentukan strategi apa yang akan dilakukan untuk menarik pelanggan. Dalam membentuk strategi, perusahaan juga harus mengetahui siapakah target konsumen perusahaan tersebut dan apa saja yang dibutuhkan oleh konsumen. Pembentukan organisasi atau tim kerja sangat berpengaruh dalam menjalankan strategi yang sudah dibentuk. Apapun yang dikerjakan oleh organisasi tersebut merupakan sebuah proses dan dalam proses pengerjaan tersebut dapat dibantu dengan adanya Information Technology (IT) untuk mempermudah pekerjaan. Jika IT mampu mendukung suatu perusahaan untuk mencapai hasil akhir, maka perusahaan dapat dikatakan berhasil dan cukup memantau keberhasilan tersebut [9].

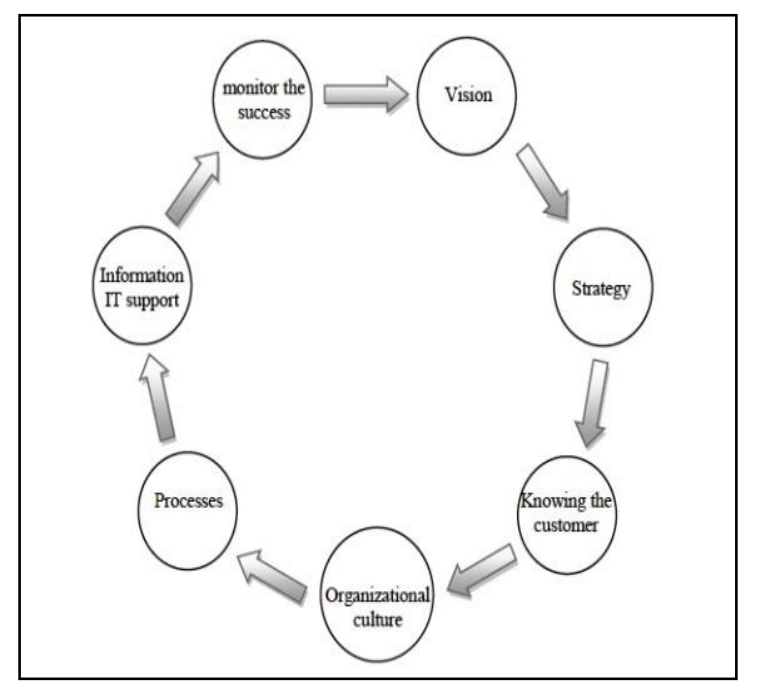

Gambar 1. CRM Cycle

\subsubsection{System Development Life Cycle (SDLC)}

System Development Life Cycle (SDLC) merupakan metode yang digunakan untuk mengembangkan sebuah sistem. Selain itu, SDLC dapat didefinisikan sebagai gambaran siklus sebuah sistem dalam tahap pengembangan sebuah sistem [10]. Berikut ini merupakan tahapan dalam SDLC, yaitu :

1) Perencanaan sistem

2) Analisis sistem

3) Perancangan sistem

4) Implementasi sistem

5) Pemeliharaan sistem

\subsubsection{Rapid Application Development (RAD)}

Prinsip dasar dari konsep RAD adalah siklus yang bertahap. RAD digunakan saat batas waktu adalah kepentingan utama dan perkembangan perangkat lunak sangat penting. Metode ini merupakan metode pengembangan 
yang jauh lebih cepat dan mendapatkan hasil dengan kualitas yang lebih baik dibandingkan dengan hasil yang dicapai melalui siklus tradisional [11]. Rapid Application Development dapat diartikan sebagai proses pembangunan perangkat lunak dengan teknik increment (bertingkat) dan iterative (berulang) dalam mengembangkan sistem [12].

\subsubsection{Structured Query Language (SQL)}

Structured Query Language (SQL) merupakan bahasa yang dirancang untuk mendapatkan informasi dari data yang disimpan di dalam relational database [13]. SQL terdiri dari dua bahasa yaitu Data Definition Language (DDL) dan Data Manipulation Language (DML). Penulisan database dalam aplikasi ini akan menggunakan salah satu turunan dari SQL yaitu MySQL [14].

\subsubsection{Unified Modeling Language (UML) versi 2.5}

Unified Modeling Language (UML) adalah bahasa pemodelan untuk sistem atau perangkat lunak yang menggunakan paradigma berorientasi objek. Pemodelan digunakan untuk menyederhanakan permasalahan yang kompleks sehingga lebih mudah dipelajari dan dipahami [15].

Beberapa jenis diagram dalam UML yang dipakai dalam penelitian ini, antara lain :

1) Use Case Diagram

Use case diagram merupakan sebuah teknik pemodelan yang sering digunakan dalam pengembangan sebuah software untuk menangkap kebutuhan fungsional dari sistem terkait. Diagram ini merepresentasikan adanya interaksi antara aktor dengan sistem. Use case diagram menggambarkan sistem menurut fungsifungsi yang sudah ditentukan. Dalam Use Case menjelaskan interaksi antara manusia (actor) dengan sistem dan pekerjaanpekerjaan tertentu yang dilakukan oleh actor.

\section{2) Class Diagram}

Salah satu diagram yang digunakan dalam pemodelan struktural adalah class diagram. Class merupakan sebuah contoh yang dapat menghasilkan sebuah objek dan merupakan inti dari pengembangan dan desain berorientasi objek. Class memiliki atribut dan fungsi operasi (method). Struktur dan deskripsi mengenai class, package, dan objek digambarkan dalam sebuah class diagram, setiap class akan berhubungan antara satu class dengan class lainnya, yang menghubungkan antar class dapat disebut dengan generalization, inheritance, atau association.

3) Activity Diagram

Activity diagram menggambarkan alur aktivitas dalam sistem yang sedang dikembangkan, seluruh keputusan yang mungkin terjadi dan bagaimana mereka berakhir. Activity diagram menggambarkan proses paralel yang mungkin terjadi pada beberapa operasi. Pembuatan activity diagram disesuaikan dengan use case diagram yang telah dibuat. 


\subsubsection{Hypertext Markup Language 5 (HTML 5), Javascript, dan PHP}

HTML merupakan kependekan dari HyperText Markup Language, bahasa ini ditulis dengan aturan kode tertentu yang digunakan untuk aplikasi web browser ([16]. Pada saat ini HTML sudah berkembang menjadi HTML 5. Bahasa ini berkembang demi mendukung teknologi terbaru agar dapat dibaca oleh manusia dan mesin.

HTML 5 merupakan standard baru untuk sebuah HTML, yang memungkinkan untuk membangun website yang lebih menarik dan interaktif. HTML 5 mendukung perbedaan platform dan didesain untuk menampilkan halaman web di Personal Computer (PC), Tablet, Smartphone, atau Smart TV [17].

Javascript merupakan sebuah bahasa yang digunakan pada website agar website tersebut menjadi lebih interaktif dan dinamis. Javascript merupakan bahasa pemrograman yang masuk dalam kategori high level programming language, bahasa pemrograman ini berjalan pada client side, berorientasi objek, dan bahasa yang digunakan untuk Asynchronous JavaScript and XML (AJAX) [19]; [18].

PHP merupakan kepanjangan dari PHP Hypertext Preprocessor adalah suatu bahasa pemrograman yang berfungsi untuk membangun suatu website dinamis. PHP ditulis beriringan dengan HTML, di mana HTML digunakan sebagai fondasi dari kerangka layout web, sedangkan PHP sebagai mesin utama. PHP berjalan pada sisi server sehingga PHP disebut juga sebagai bahasa Server Side Scripting[16].

\subsubsection{CodeIgniter}

CodeIgniter merupakan aplikasi opensource berupa framework PHP. CodeIgniter memiliki model MVC (Model, View, Controller) yang berfungsi untuk membangun web yang dinamis, selain itu CodeIgniter juga kompatibel dengan PHP5. MVC memiliki tiga bagian yang berbeda, yaitu model berfungsi untuk lapisan database, view berfungsi untuk tampilan pada web dan controller berfungsi untuk mengontrol setiap tombol atau tautan pada web [20]. Versi yang digunakan dalam pengembangan aplikasi adalah 3.0.4.

\subsubsection{Testing}

Testing merupakan proses eksekusi program atau sistem secara intens untuk menemukan error. Testing yang digunakan untuk menguji sistem usulan ini menggunakan black box testing. Black Box dilakukan hanya untuk mengamati hasil eksekusi melalui data uji dan memeriksa fungsional dari perangkat lunak, atau dapat diartikan juga kita hanya melihat bagian luarnya saja tanpa tahu detail prosesnya [19].

\subsection{Desain Sistem}

Untuk memecahkan masalah yang telah dijabarkan dalam bagian pendahuluan, maka telah didesain sebuah sistem dan dikembangkan dalam bentuk aplikasi web. Bagian berikut ini akan menjelaskan proses dan detil dari sistem dan aplikasi yang telah dikembangkan.

Dengan menggunakan metode RAD, langkah-langkah yang telah dilakukan untuk mengembangkan sistem adalah: 
1) Penetapan user requirements dengan menggunakan metode wawancara dengan pemilik, observasi kegiatan harian, dan studi literatur.

2) Pembuatan desain sistem menggunakan UML 2.5 yang akan dijelaskan dalam subbab selanjutnya.

3) Pengembangan prototipe sistem selama beberapa iterasi yang senantiasa dikomunikasikan dengan pengguna sistem untuk setiap iterasinya.

4) Setelah memperoleh sistem yang dianggap stabil, maka dilakukan pengetesan sistem untuk memperoleh feedback dari user.

5) Melakukan perbaikan-perbaikan sistem berdasarkan feedback dari user dan melakukan serah terima sistem.

\subsubsection{Use Case Diagram Sistem}

Use Case Diagram sistem reservasi online restoran 3 Wise Monkeys dapat dilihat dalam pada Gambar 2.

\subsubsection{Activity Diagram Sistem}

Proses utama dari Sistem Reservasi Online dan Customer Relation Management Restoran 3 Wise Monkeys digambarkan dalam bentuk activity diagram. Contoh activity diagram dari reservasi, dan membuat program berhadiah dapat dilihat pada Gambar 2 (setelah daftar pustaka).

\subsubsection{Class Diagram Sistem}

Pemodelan struktural bertujuan untuk menggambarkan struktur dari sistem usulan. Pemodelan struktural digambarkan oleh Class Diagram. Gambar 3 (setelah daftar pustaka) merupakan class diagram dari Sistem Reservasi Online dan Customer Relation Management pada Restoran 3 Wise Monkeys.

\subsubsection{Table Relationship Diagram}

Gambar 4 (setelah daftar pustaka) menunjukkan table relationship diagram dari sistem usulan. Gambar ini menunjukkan hubungan setiap tabel dan primary key dari masing - masing tabel.

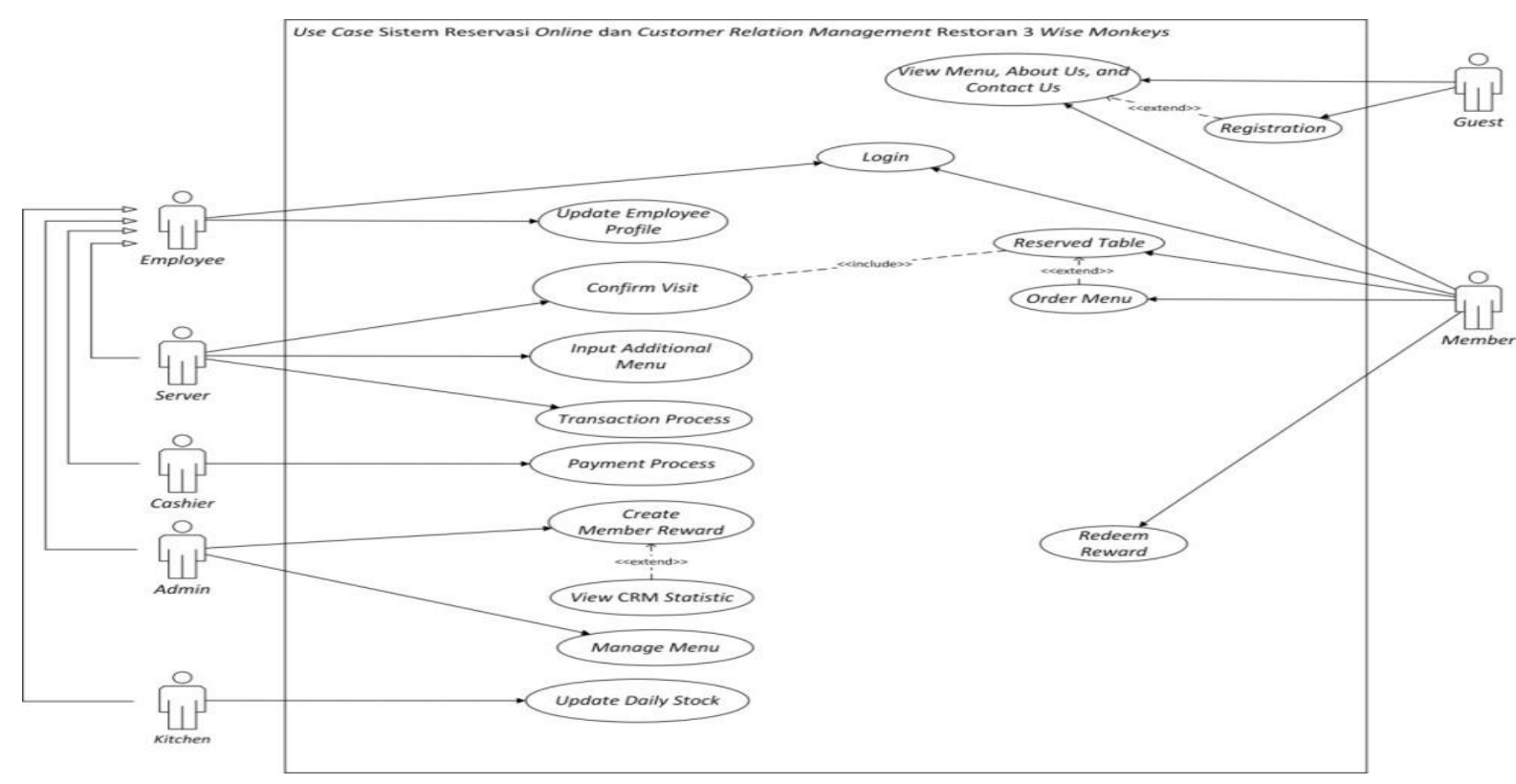

Gambar 2. Use Case Sistem Reservasi Online dan CRM Restoran 3 Wise Monkeys 


\subsubsection{User Interface}

Berikut ini merupakan tampilan dari sistem reservasi online :

1) Halaman utama

Gambar 5 merupakan tampilan halaman utama dari website reservasi online 3 Wise Monkeys. Dari halaman utama ini, pengguna dapat mengakses fungsi-fungsi yang ada dalam sistem seperti yang dalam desain sistem di bagian 2.1. Selain pengguna tamu (guest), pengguna yang lain harus melakukan login terlebih dahulu untuk mengakses fungsi.

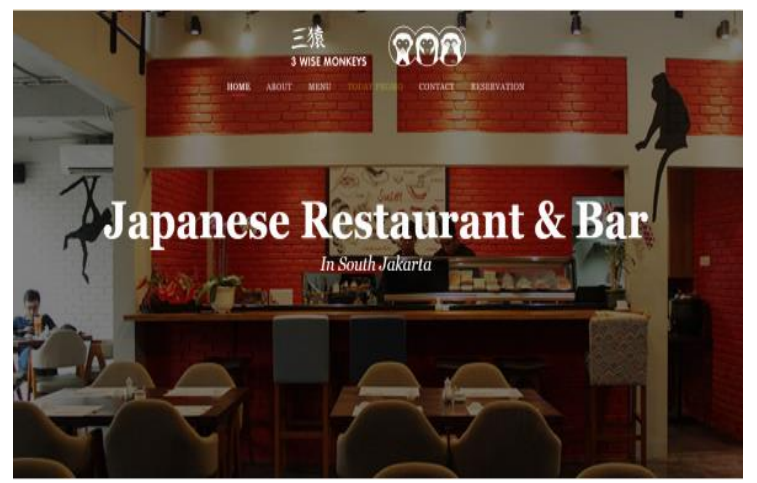

Gambar 5. Halaman Utama Website 3

\section{Wise Monkeys}

2) Formulir reservasi

Untuk dapat melakukan reservasi pelanggan harus mengisi formulir reservasi terlebih dahulu, dan memilih meja yang diinginkan (Gambar 6).

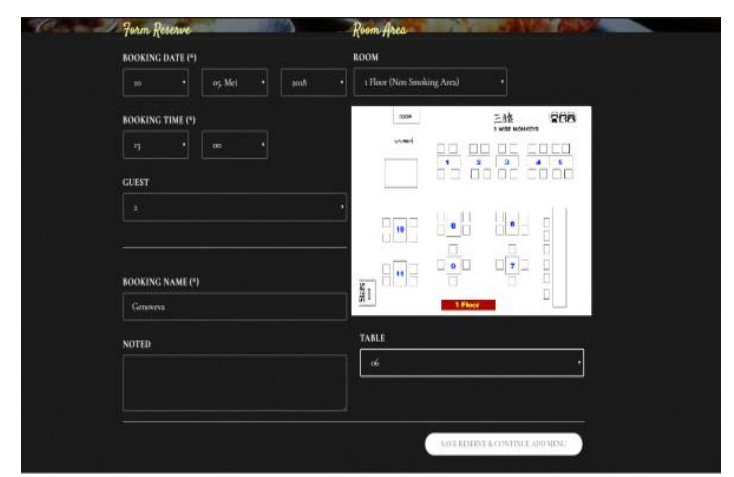

Gambar 6. Formulir Reservasi
3) Email reservasi

Setelah selesai mengisi formulir reservasi, maka pelanggan akan mendapat email konfirmasi reservasi seperti Gambar 7.

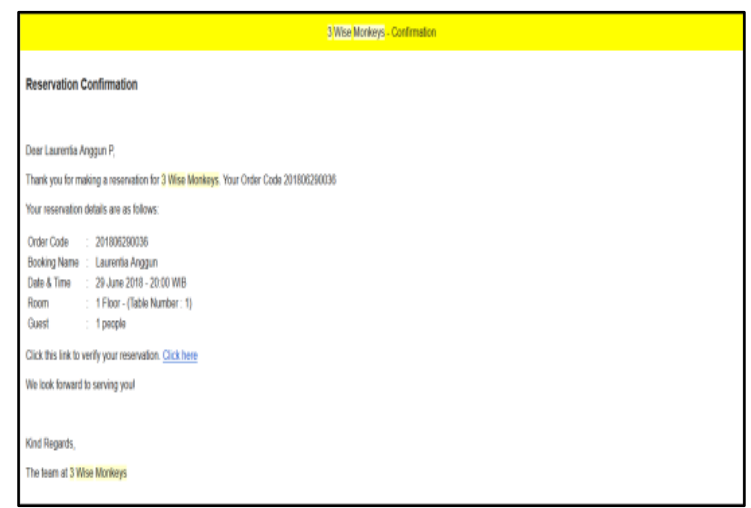

Gambar 7. Email Konfirmasi Reservasi

4) Member reward

Data pelanggan yang melakukan reservasi online dan melakukan transaksi akan terkumpul, dan dari data tersebut restoran dapat membuat program berhadiah dengan kategori yang ditentukan oleh restoran. Gambar 2.8 merupakan contoh dari nama pemenang dari kategori yang sudah ditentukan

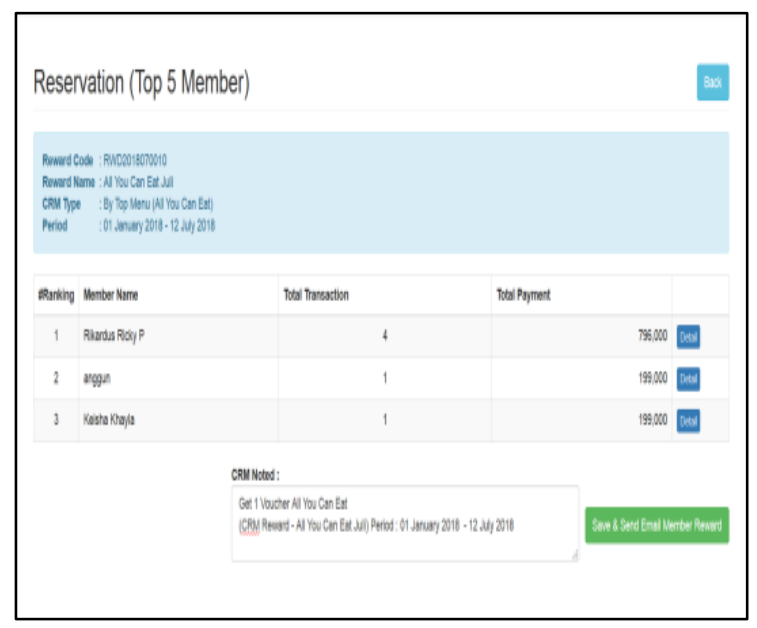

Gambar 8. Daftar Nama Pemenang

Gambar 9 menunjukan bahwa sistem sudah berhasil mengirim email kepada para pelanggan yang memenangkan program berhadiah. 


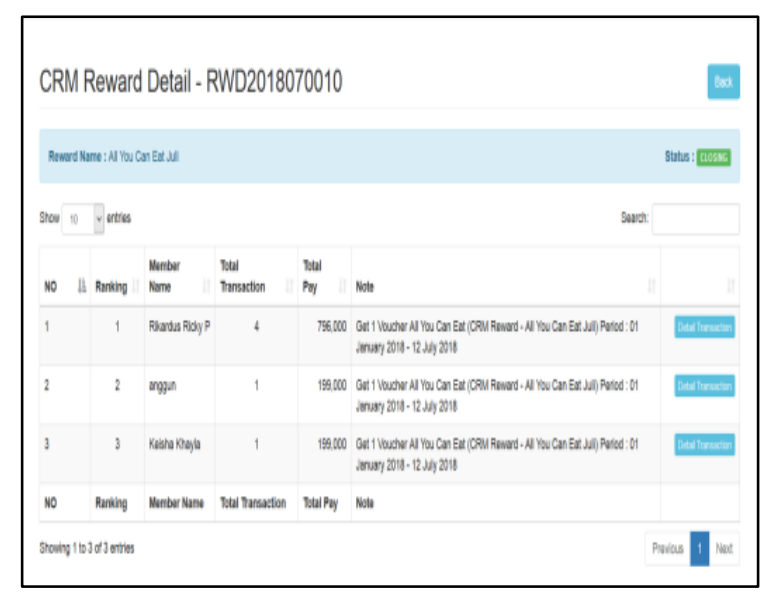

Gambar 9. Notifikasi Nama Pemenang yang

\section{Sudah Dikirim Email}

Pelanggan yang memenangkan program berhadiah akan mendapatkan email seperti Gambar 10, dan dapat ditukarkan kepada restoran sesuai dengan tanggal yang sudah ditentukan.

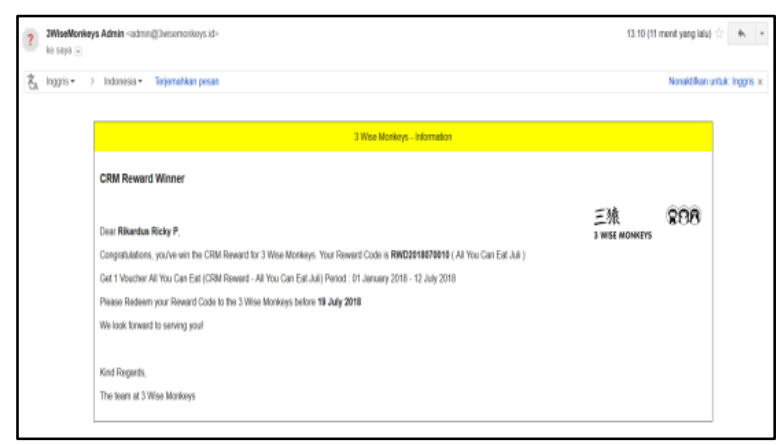

Gambar 10. Email yang Diterima Oleh

\section{Pemenang}

\subsubsection{Testing}

Pengujian dilakukan dengan metode black box testing. Metode black box testing bertujuan untuk menguji keseluruhan fungsi pada sistem yang sudah berjalan dengan baik dan layak digunakan. Pengujian sistem ini dilakukan dengan pemilik dari restoran 3 Wise Monkeys Bapak Toar Christopher yang berlokasi di restoran 3 Wise Monkeys pada tanggal 27 Mei 2018. Semua skenario dalam sistem sudah diuji dan berjalan dengan baik.

\section{KESIMPULAN}

Pengerjaan penelitian ini telah menghasilkan sistem reservasi online bagi para pelanggan yang ingin datang ke restoran 3 Wise Monkeys tanpa harus menunggu untuk mendapatkan meja. Sistem ini telah dirancang sesuai permintaan pemilik restoran 3 Wise Monkeys. Adapun sistem ini telah memenuhi kebutuhan pelanggan maupun pihak restoran, antara lain :

1) Pelanggan dapat dengan mudah memesan meja yang diinginkan dengan adanya sistem reservasi online yang berbasis web sehingga dapat diakses kapan saja dan dimana saja.

2) Pelanggan yang melakukan sistem reservasi online dapat mengetahui apabila meja yang akan dipilih sudah ditempati pelanggan lain dan makanan yang akan di pesan sudah habis.

3) Pelanggan yang melakukan sistem reservasi online dapat memilih menu dan meja yang diinginkan terlebih dahulu tanpa harus menunggu proses pembuatan makanan atau minuman terlalu lama dan pelanggan dapat langsung menikmati makanan atau minuman saat telah tiba di restoran.

4) Bagi pemilik restoran dapat memberikan hadiah bagi para pelanggan yang sering melakukan reservasi atau melakukan transaksi terbanyak.

5) Pemilik dapat melihat statistik transaksi restoran, statistik ini diambil dari data - data pelanggan yang melakukan reservasi melalui online. Data yang terkumpul tersebut digambarkan dalam bentuk diagram dan tabel data. 
6) Sistem ini juga mempermudah restoran untuk manajemen menu, seperti menambah, mengubah, atau menghapus menu.

7) Kitchen juga dapat lebih mudah mengetahui stok menu yang akan habis, atau sudah habis.

Saran yang dapat diusulkan untuk pengembangan sistem reservasi online ini adalah :

1) Sistem reservasi online dibuat dalam bentuk aplikasi.

2) Sistem reservasi dapat terintegrasi dengan sistem yang dimiliki restoran saat ini.

3) Adanya sistem pembayaran apabila akan melakukan pemesanan menu terlebih dahulu.

4) Pemesanan menu tambahan dapat dilakukan dalam sistem, tanpa memesan secara manual.

\section{DAFTAR PUSTAKA}

[1] Hospitality Technology, "Restaurant Technology Study 2016," Chicago, 2016.

[2] F. Demicco, C. Cobanoglu, J. Dunbar, R. Grimes, C. Chen, and K. James R, Restaurant Management: A Best Practices Approach. Kendall Hunt Publishing, 2015.

[3] A. Needles and G. Thompson, "Social Media Use in the Restaurant Industry: A Work in Progress," Cent. Hosp. Res. Publ., vol. 13, no. 7, pp. 6-16, 2013.

[4] Sheryl E. Kimes, "How Restaurant Customers View On-line Reservations," Cornell Hosp. Rep., vol. 9, no. 5, 2009.

[5] B. M. A. Almohaimmeed, . "Restaurant quality and customer satisfaction.," Int. Rev. Manag. Mark., vol. 7(3), pp. 42-49., 2017.

[6] A. Sasongko, J. S. Informasi, F. Ilmu, and T. Informasi, "Aplikasi pemesanan makanan dan minuman pada rumah makan," p. 18, 2010.

[7] H. Ariefianto, M. Dani, and A. Nugraha, "Perancangan Dan Implementasi
Aplikasi Pemesanan Makanan Dan Minuman Berbasis Client Server Dengan Platform Android ( Studi Kasus Waroeng Steak And Shake )," Inf. Syst. , Fac. Comput., vol. 1-16, 2016.

[8] H. S. Soliman, "Customer Relationship Management and Its Relationship to the Marketing," Int. J. Bus. Soc. Sci., vol. 2, no. 10, pp. 166-182, 2011.

[9] B. Milovic, "Application of Customer Relationship Management Strategy ( $C R M$ ) in Different Business Areas," Univ. Novi Sad, Serbia, vol. 9, pp. 341354, 2012.

[10] P. Isaias and T. Issa, "Information System Development Life Cycle Models," High Lev. Model. Methodol. Inf. Syst., pp. 2140, 2015.

[11] J. Martin, "Rapid Application Development," Six Sigma Softw. Dev. Second Ed., 1991.

[12] S. Aswati, M. S. Ramadhan, A. U. Firmansyah, and K. Anwar, "Studi Analisis Model Rapid Application Development Dalam Pengembangan Sistem Informasi," J. Matrik, vol. 16, no. 2, p. 20, 2017.

[13] R. Elmasri and S. B. Navathe, "Fundamental of database systems," p. 1201, 2010.

[14] D. Gosselin, D. Kokoska, and R. Easterbrook, "PHP Programming With MYSQL," 2011.

[15] A. Dennis, B. H. Wixom, and D. Tegarden, System Analysis and Design: An object-oriented approach with UML, 5th ed. 2015.

[16] C. Rajesh and K. S. V. K. Srikanth, "Research on HTML5 in Web Development," Int. J. Comput. Sci. Inf. Technol., vol. 5, no. 2, pp. 2408-2412, 2014.

[17] I. Typecasting and T. Equality, Advanced JavaScript Essentials. .

[18] S. Suehring, "Step by Step JavaScript," Microsoft, vol. 3, 2013.

[19] G. D. Everett and R. McLeod Jr., Software Testing Software Development Life Cycle, vol. 5, no. 3. 2007.

[20] A. Griffiths, Codeigniter 1.7 Professional Development. 2010. 

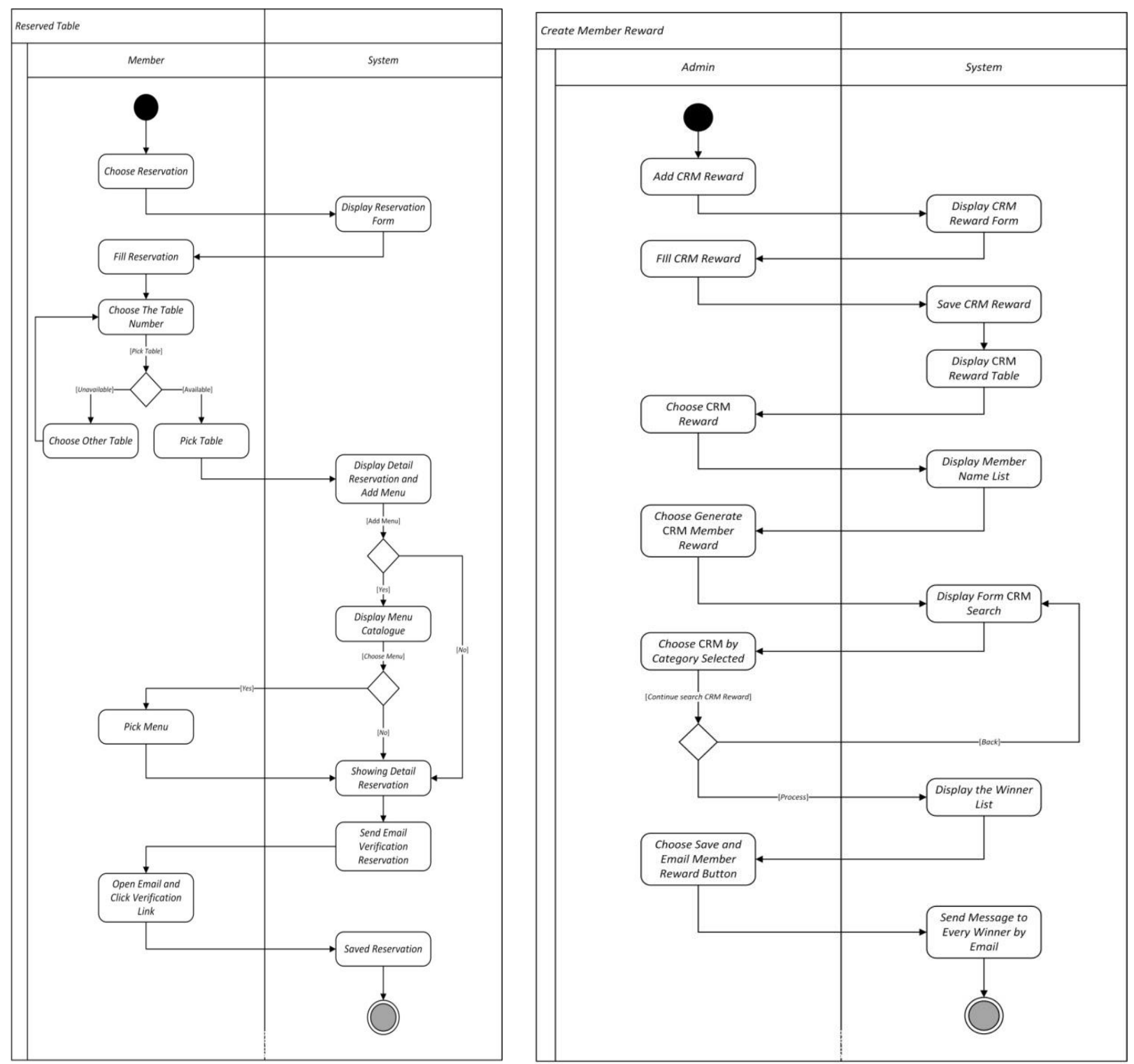

Gambar 2. Activity Diagram Reserved Table dan Create Member Reward 


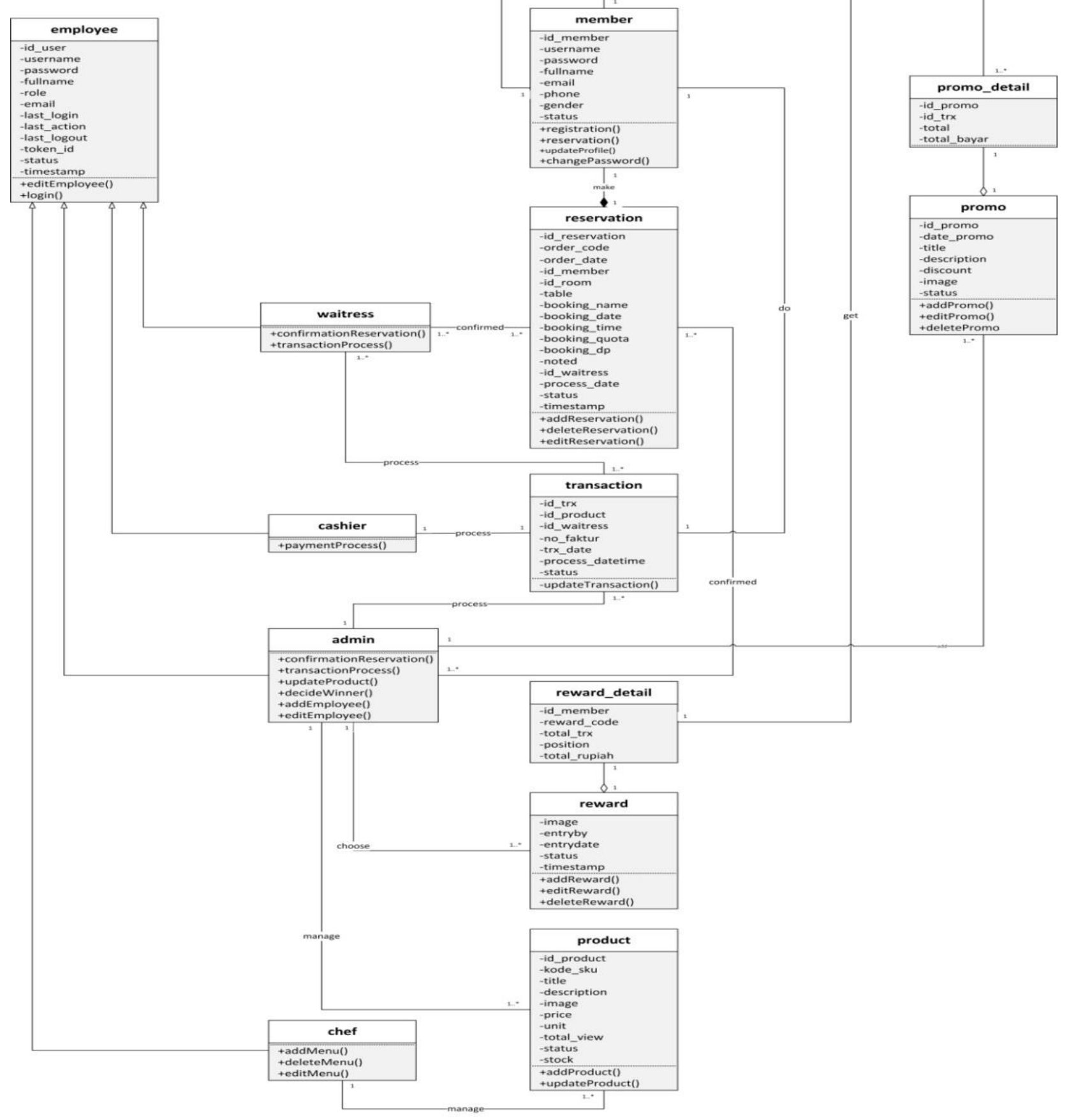

Gambar 3. Class Diagram Sistem Reservasi Online dan Customer Relation Management Restoran 3 Wise Monkeys 

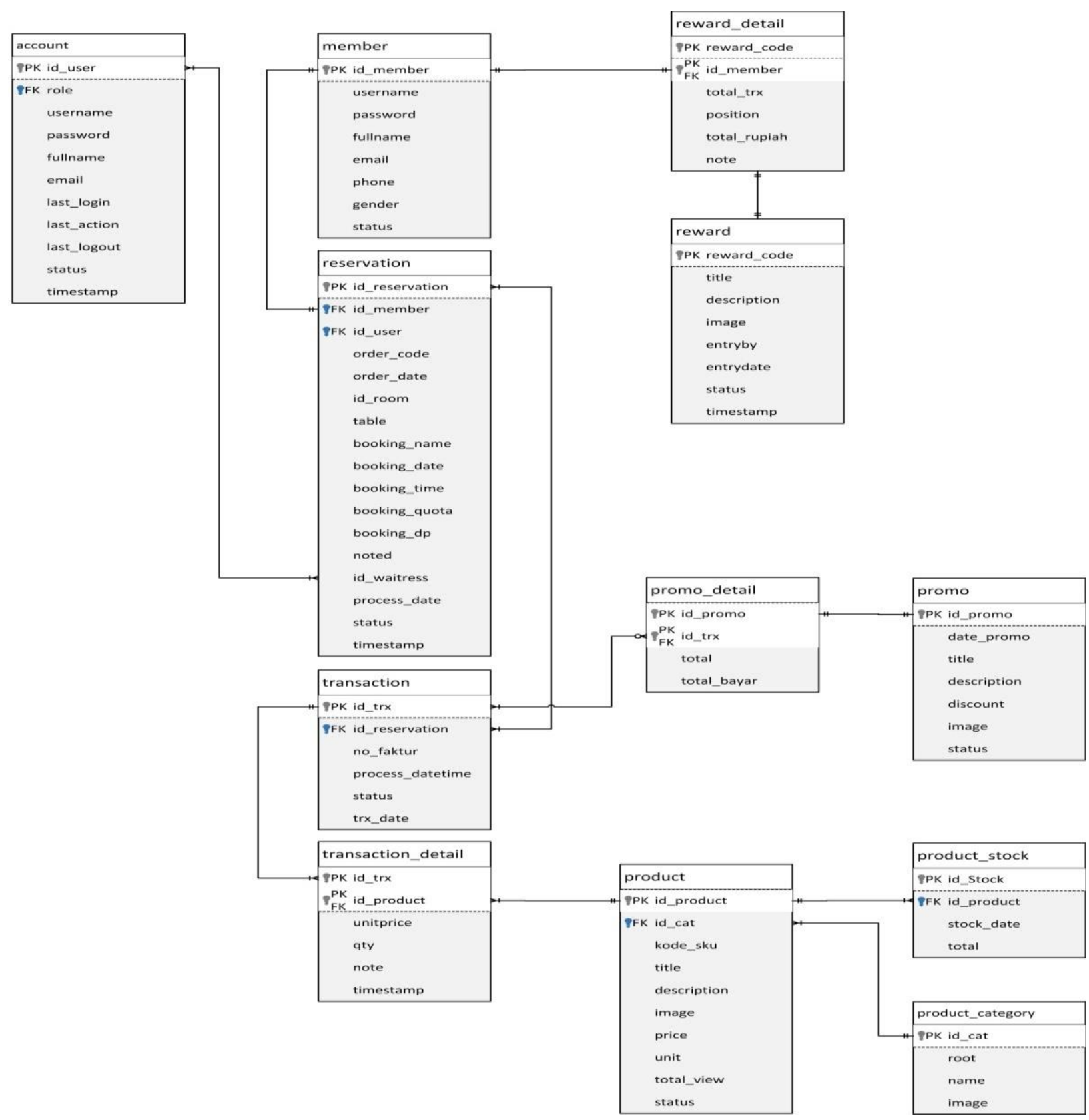

Gambar 4. Table Relationship Diagram : Sistem Reservasi Online dan Customer Relation Management Restoran 3 Wise Monkeys 